\title{
Comparison of Subjective Evaluation and Adults Voice to Acoustic Features of Children Voice
}

\author{
HARADA Naoya ${ }^{\mathrm{a}}$, NAKATOH Yoshihisa ${ }^{\mathrm{a}^{*}}$ \\ ${ }^{a}$ Kyushu Institute of Technology, \\ 1-1 Sensui-cho, Tobata-ku, Kitakyushu-shi, Fukuoka 804-8550, Japan \\ *nakatoh@ecs.kyutech.ac.jp
}

\begin{abstract}
Currently, Japan is an aged society, and about $30 \%$ of the total population of Japan is elderly. Also, the number of shipments of hearing aids in Japan has increased about twice in 20 years. It is thought that the proportion of elderly people will continue to increase in the future, and the demand for hearing aids will increase more and more. However, under such circumstances, there is a survey result that about $40 \%$ of hearing aid owners are dissatisfied with conversation with children. Therefore, we analyze the difference of how to hear children voice of elderly people and adults as basic study. Subjective evaluation was conducted using children voice from 6 to 12 years old and the acoustic features of the voice was analyzed. In the correlation between the feeling of voice height and the fundamental frequency, we found that there is a weak positive correlation with correlation coefficient 0.341 in the elderly. In adults, we found that correlation coefficients were 0.646 and positive correlation. From this result, it is quantitatively clear that it is difficult for elderly people to distinguish the voice height compared to adults. Moreover, compared to adults voice, children voice are high both in the fundamental frequency and the formant frequency, and some vowels are found to be higher than $2[\mathrm{kHz}]$.
\end{abstract}

Keywords: children voice, fundamental frequency.

\section{Introduction}

Currently, Japan is an aged society, and about $30 \%$ of the total population of Japan ${ }^{(1)}$ is elderly. Furthermore, it is expected that the aging will progress further in the future. Also, the number of shipments of hearing aids in Japan has doubled from 1990 to $2015^{(2)}$, and the number of hearing aid owners in 2015 is about 2 million. It is thought that the proportion of elderly people will continue to increase in the future, and the demand for hearing aids will increase more and more. However, under such circumstances, there is a survey result that about $40 \%$ of hearing aid owners are dissatisfied with conversation with children ${ }^{(3)}$. Therefore, we study the hearing improvement of the hearing aid user as the final goal. In this research, as a basic study, we analyze differences in how to hear children voice of elderly people and adults. Specifically, we conduct an evaluation experiment of children voice for the elderly people and adults. Then compare the results. In addition, factor analysis is conducted on the evaluation result, and factors which affect the way of hearing the children voice are specified. Next, we compare how to hear the elderly people and adults for each factor and compare the relationship with the acoustic features of the children voice. Finally, we compare the acoustic features of children voice and adults voice.

\section{Evaluation experiment of children voice}

\subsection{Children voice}

The children voice used is 5 words of 78 boys aged 6 to 12 in CIAIR-VCV. These five words were connected across the silent section, and 78 experimental voices were created.

\subsection{Selection of evaluation items}

In this research, in order to compare how to hear the children voice of the elderly people and adults, we conducted an evaluation experiment. For the evaluation items, words expressing the features of voice by previous research ${ }^{(4)}$ and its negative form were used. Furthermore, we presented children voice to five adult men in their twenties by headphones. We asked them to freely describe how adult men felt, and collected words expressing the characteristics of voice. Finally, 13 evaluation items were selected and used 
in this study.

\subsection{The method of experiment}

78 children voices were presented by headphones to five elderly people in their seventies and five adult men in their twenties, and each voice was evaluated in five stages from +2 to -2 .

\subsection{The result of experiment}

Fig.1 shows the evaluation result of "Voice height" in which the difference between elderly people and adults remarkably appears among 13 items. From this result, we found that as the age of children increases, adults evaluate "High voice" to "Low voice". On the other hand, we found that the elderly people had almost constant evaluation. From this, we considered that it may be difficult for elderly people to distinguish the voice height.

\section{Factor analysis}

From the evaluation experiment of children voice, it turned out that the way of feeling the voice height differs between elderly people and adults. However, no difference was found for other evaluation items. Therefore, when adults evaluate children voices, we identify by factor analysis ${ }^{(5)}$ what factors are affecting, and compare elderly people and adults for each factor.

Table 1 shows the results of factor analysis using the evaluation results of adults. Looking at each factor, Factor 1 is made up of fluency, existence of breath leakage and noise, voice tremor and stability. Therefore, I named Factor 1 is "Voice quality and Speaking style ". Since Factor 2 consists of strength and accent, we named as "Voice strength". Since Factor 3 consists of voice height, reverberation, brightness, spreading, we named as "Ease of hearing". The last Factor 4 was named as a factor of "Voice speed".

Next, using the results of the evaluation experiment of children voice, we compare the variation of the evaluation of elderly people and adults for each factor. Table 2 shows the average value and standard deviation of the elderly and adult's evaluation. From this result, it can be seen that the variation in the evaluation of the elderly people is smaller for Factor 4 voice speed than for adults. From this, it is considered that elderly people may have difficulty distinguishing the speech speed.

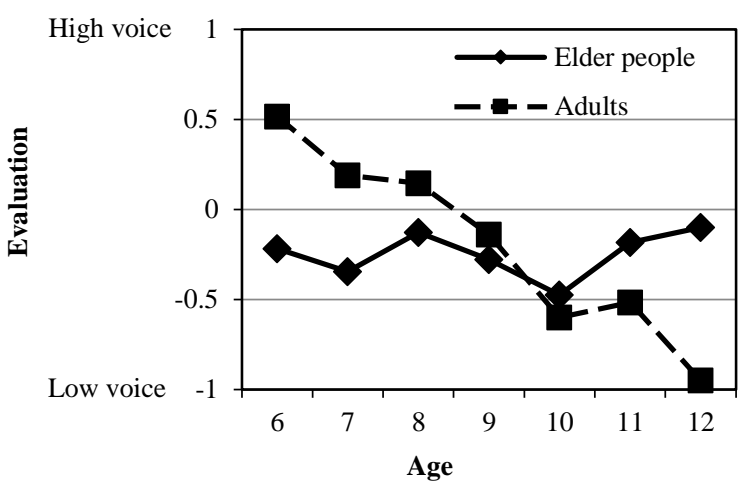

Fig.1 Evaluation of elderly and adults

Table 1 Factor of children voice

\begin{tabular}{|c|c|}
\hline \multicolumn{2}{|r|}{ Factor 1 "Voice quality and Speaking style" } \\
\hline$\bullet$ & Breathy voice / Non-breathy voice \\
\hline$\bullet$ & Speech interspersed with noises from inside the mouth / \\
\hline & Speech not interspersed with noises from inside the mouth \\
\hline • & Unsteady voice / Fluent voice \\
\hline$\bullet$ & Trembling voice / Non-trembling voice \\
\hline$\bullet$ & Feeble voice / Forceful voice \\
\hline \multicolumn{2}{|r|}{ Factor 2 "Voice strength" } \\
\hline$\bullet$ & Weak accent / Strong voice \\
\hline$\bullet$ & Strained voice / Non-strained voice \\
\hline$\bullet$ & Weak accent / Strong accent \\
\hline \multicolumn{2}{|r|}{ Factor 3 "Ease of hearing" } \\
\hline$\bullet$ & Low voice / High voice \\
\hline$\bullet$ & Hoarse and rasping voice / Beautiful and clear voice \\
\hline$\bullet$ & Dark voice / Bring voice \\
\hline$\bullet$ & Muffled voice / Modulated and resounding voice \\
\hline \multicolumn{2}{|r|}{ Factor 4 "Voice speed" } \\
\hline$\bullet$ & Slow utterance / Fast utterance \\
\hline
\end{tabular}

\section{Correlation between how to feel the children voice and acoustic features}

Based on the results of evaluation experiments and factor analysis of children voice, the elderly people may possibly have difficulty distinguishing themselves from the voice height and the speech speed. Therefore, the voice height (fundamental frequency) and speech rate of the children voice are obtained and the correlation with the actual evaluation is compared. The unit of the voice rate was set to [morae / sec], and it was calculated using the interval from the beginning to the end of the word in 5 words ( 25 morae). The comparison result is shown in Fig.2.

In the correlation between the feeling of voice height and the fundamental frequency, we found that there is a weak 
positive correlation with correlation coefficient 0.341 in the elderly. In adults, we found that correlation coefficients were 0.646 and positive correlation. From this result, it is quantitatively clear that it is difficult for elderly people to distinguish the voice height compared to adults. On the other hand, correlation between speech rate and evaluation was found to have a strong positive correlation with the correlation coefficient of 0.718 in the case of elderly people. In adults, it was also found that the correlation coefficient was 0.795 , indicating a strong positive correlation. From these results, it was found that both the elderly and adults were able to recognize the speed of utterance almost correctly.

\section{Comparison between children and adults voice}

Finally, we compare acoustic features of children voice and adults voice. Fig. 3 shows comparison of voice height (fundamental frequency) and speech rate. From the figure, children voice is about $100[\mathrm{~Hz}]$ higher in fundamental frequency and about 1.5 [morae] in speech rate than adult voice. From this, it is considered that when the elderly people feel that it is difficult to hear the children voice, it may be caused by high voice unique to children voice or unsteady voice.

Next, the formant frequency of children voice and adults voice were compared. We think about the formant frequency F1 and F2. F1 and F2 are necessary information for recognizing vowels. Fig. 4 shows a comparison of the

Table 2 Comparison of evaluation

\begin{tabular}{|l|c|c|c|c|}
\hline \multicolumn{2}{|c}{} & $\begin{array}{c}\text { Elderly } \\
\text { People }\end{array}$ & Adults & Difference \\
\hline \multirow{4}{*}{ Factor 1 } & Average & 0.051 & -0.037 & 0.088 \\
\cline { 2 - 5 } & $\begin{array}{l}\text { Standard } \\
\text { deviation }\end{array}$ & 0.672 & 0.723 & 0.051 \\
\hline \multirow{5}{*}{ Factor 2 } & Average & -0.114 & 0.176 & 0.290 \\
\cline { 2 - 6 } & $\begin{array}{l}\text { Standard } \\
\text { deviation }\end{array}$ & 0.700 & 0.688 & 0.011 \\
\hline \multirow{5}{*}{ Factor 3 } & Average & -0.049 & -0.167 & 0.118 \\
\cline { 2 - 6 } & $\begin{array}{l}\text { Standard } \\
\text { deviation }\end{array}$ & 0.792 & 0.840 & 0.047 \\
\hline \multirow{2}{*}{ Factor 4 } & $\begin{array}{l}\text { Standard } \\
\text { deviation }\end{array}$ & 0.752 & 0.943 & 0.192 \\
\cline { 2 - 6 } & Average & 0.056 & -0.003 & 0.059 \\
\hline
\end{tabular}

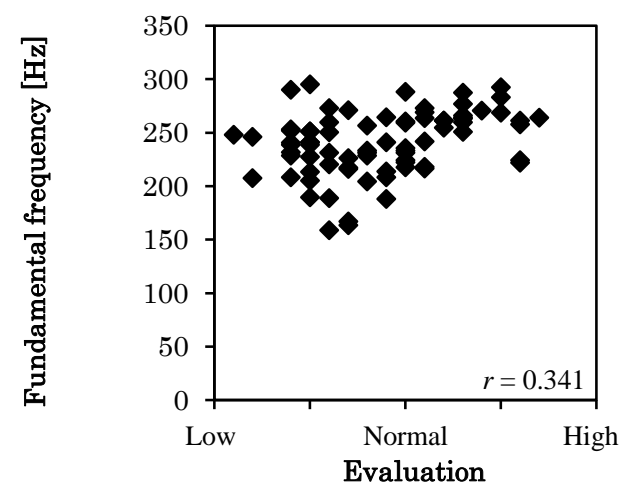

(a) Voice height (Elderly people)

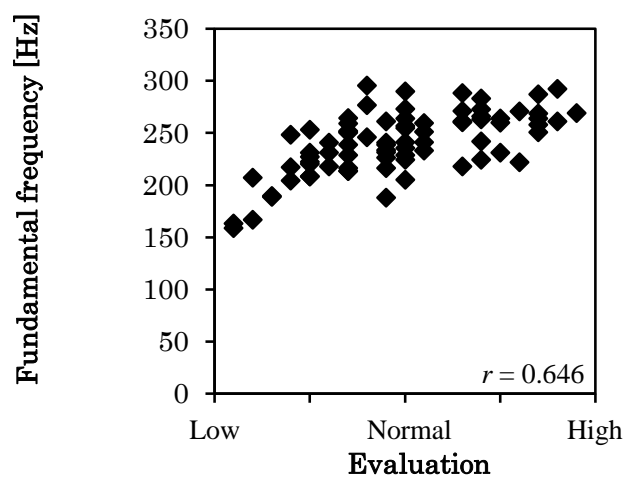

(b) Voice height (Adults)

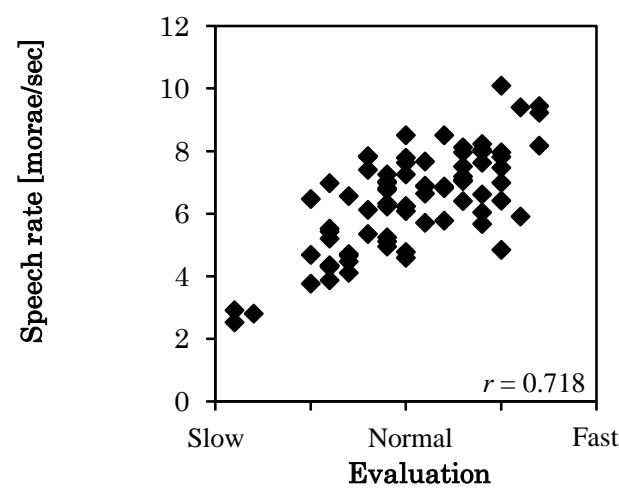

(c) Voice speed (Elderly people)

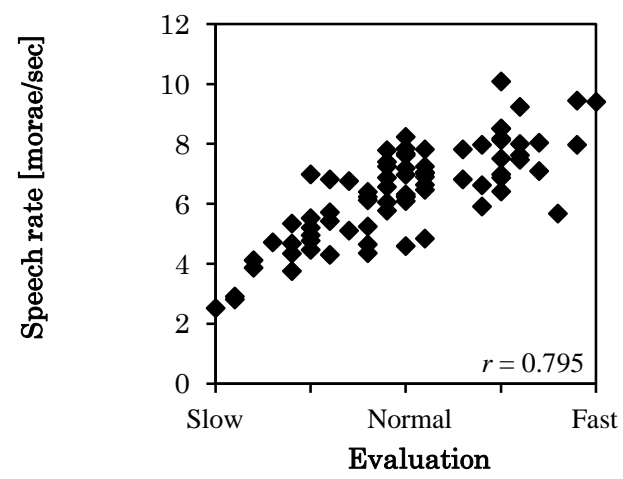

(d) Voice speed (Adults)

Fig. 2 Correlation between evaluation and acoustic features 
formant frequency of children voice and adults voice. From this figure, we found that the children voice is F1 higher by about $230[\mathrm{~Hz}]$ and F2 higher by about $500[\mathrm{~Hz}]$ on average than the adults. In F 2, it is found that / i /, / e /, and / u / are higher than $2[\mathrm{kHz}]$. Fig. 5 shows the hearing level of one of elderly subjects. For this subject, the hearing level sharply decreases for sounds with frequencies above 2 [kHz]. Elderly people using hearing aids are also considered to have similar hearing level. Therefore, elderly people may be unable to perceive vowels of / i /, / e /, / u /.

\section{Conclusions}

In this study, we examined the acoustic features of children voice as a basic study to make it easier for hearing aid user to hear children voice. As a result, it was quantitatively clarified that elderly people are more difficult to distinguish the heights of voices than adults. In addition, compared to adults voice, children voice is high both in fundamental frequency and formant frequency, it seems that it is difficult for elderly people to perceive vowels. In the future, we are planning to applicate this result to examine if it makes the hearing aid user hear the children speech easily.

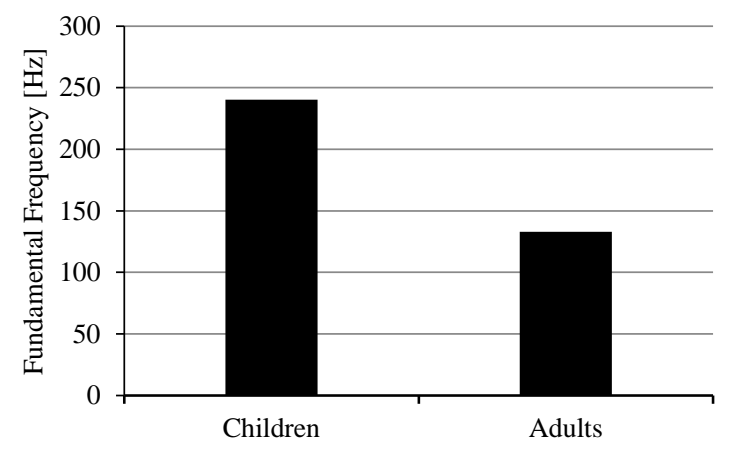

(a) Fundamental frequency

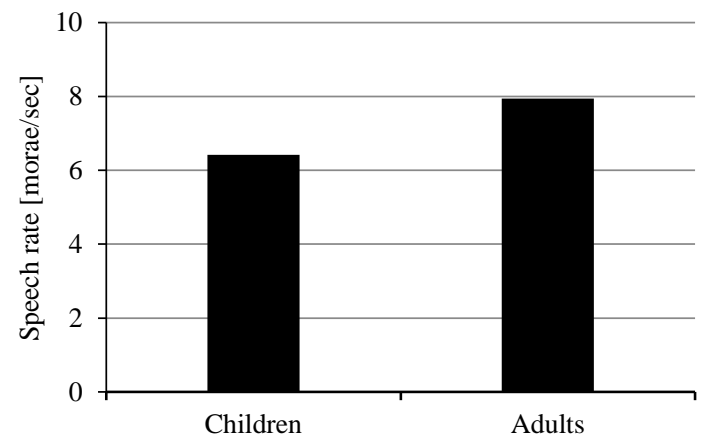

(b) Speech rate

Fig. 3 Comparison between children and adults voice

\section{References}

(1) Statistics Japan : "Population Estimates", 2017

(2) Anovum : "Trends in shipments of Japanese domestic hearing aids", 2016

(3) “JapanTrak2015”, 60-62, 2015

(4) Takeshi Miyazaki : "Selection of Japanese adjectives for characterizing elderly speech", Spring Meeting Acoustical Society of Japan, 2008

(5) Hiroshi Shimizu : "An introduction to the statistical free software HAD : Suggestion to improve teaching, learning and practice data analysis", Journal of Media, Information and Communication, 2016

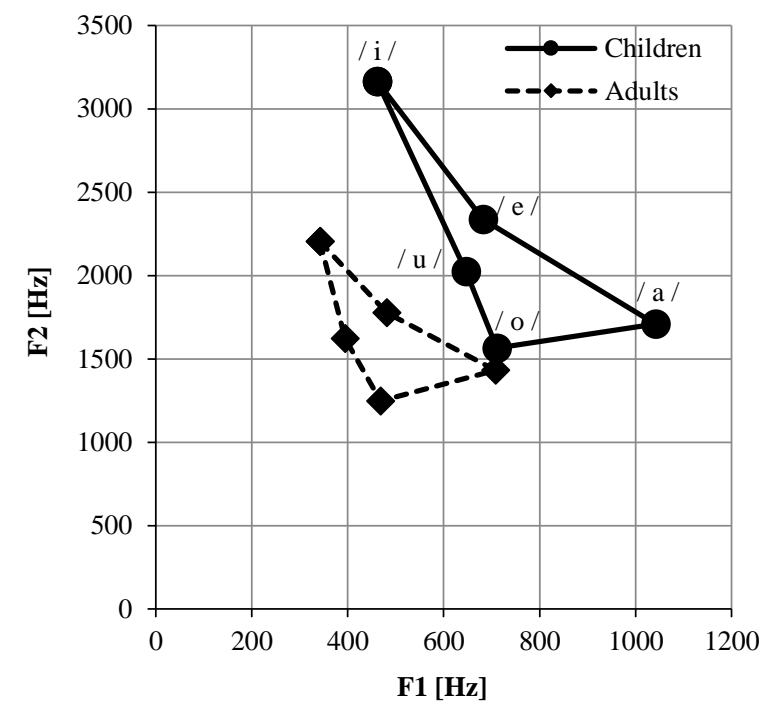

Fig.4 Formant frequency of children and adults voice

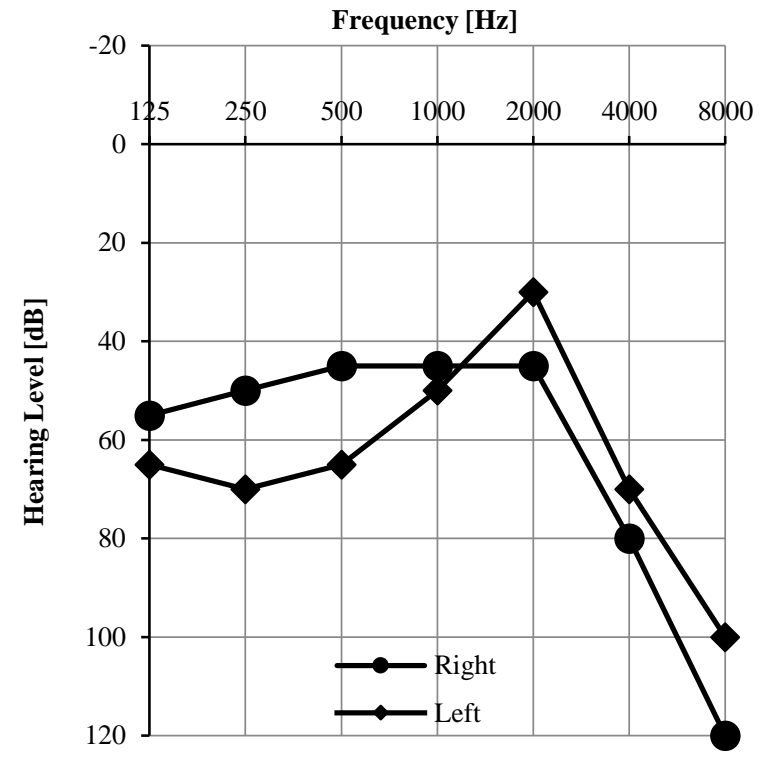

Fig.5 Hearing level (Elderly people) 